\title{
Involvement of Esterase in Phytotoxicity of a New Pyrrolinone Compound, Methyl 1-[1-(3,5-Dichlorophenyl)-1-methylethyl]-2,3- dihydro-4-methyl-2-oxo-3-phenyl-1H-pyrrole-3-carboxylate, to Early Watergrass (Echinochloa oryzicola) and Rice (Oryza sativa)
}

\author{
Seiji Yamato, ${ }^{*}$ Takafumi Fusaka and Yasushi TANAKA \\ Agricultural Research Laboratories, Technical division, Sumitomo Chemical Takeda Agro Company, Ltd., \\ 2-1 Takatsukasa 4-Chome, Takarazuka, Hyogo 665-0051, Japan
}

(Received March 1, 2005; Accepted July 11, 2005)

\begin{abstract}
A new pyrrolinone compound, methyl 1-[1-(3,5-dichlorophenyl)-1-methylethyl]-2,3-dihydro-4-methyl-2-oxo-3phenyl-1H-pyrrole-3-carboxylate (PC-1), has herbicidal activity against early watergrass (Echinochloa oryzicola). This compound showed good selectivity between rice (Oryza sativa) and early watergrass due to the introduction of a methoxycarbonyl group into the pyrrolinone structure. To elucidate the mechanism of PC-1's phytotoxicity, the effects of esterase inhibitors (triphenyl phosphate, tributyl phosphate and fenitrothion) and a cytochrome P450 monooxygenase inhibitor (1-aminobenzotriazole) on the actions of PC-1 were examined. Triphenyl phosphate and fenitrothion reduced the phytotoxicity of PC-1 in hydroponics and greenhouse tests. Porcine liver esterase converted PC-1 to 1-[1-(3,5-dichlorophenyl)-1-methylethyl]-4-methyl-3-phenyl-3-pyrrolin-2-one (PC-2) and this reaction was inhibited by triphenyl phosphate. The PC-2 content of early watergrass treated with PC-1 was 4 times that of rice. These results suggest that PC-1 is a prodrug and is converted to PC-2 by esterase, and that the amount of PC-2 produced in PC-1-treated plants is related to the sensitivity of early watergrass and rice to PC-1. (C) Pesticide Science Society of Japan
\end{abstract}

Keywords: esterase, pyrrolione, prodrug, phytotoxicity, early watergrass, rice.

\section{INTRODUCTION}

Early watergrass (Echinochloa oryzicola Vasing.) is one of major problem weeds in paddy fields in Japan. ${ }^{1)}$ Echinochloa species including early watergrass infest $87 \%$ of paddy fields. ${ }^{1)}$ Controlling these species is necessary for rice cultivation.

We found a new pyrrolinone compound, methyl 1-[1-(3,5dichlorophenyl)-1-methylethyl]-2,3-dihydro-4-methyl-2-oxo3-phenyl-1H-pyrrole-3-carboxylate (PC-1), with herbicidal activity against early watergrass (Fig. 1).,3) PC-1 at $2.5 \mathrm{~g}$ ai/a showed good control of early watergrass up to the 2.5-leaf stage and safety in rice transplanted at a depth of zero $\mathrm{cm}$ (the growth point of rice plants is located at the surface of the soil). On the other hand, at $10 \mathrm{~g}$ ai/a it did not cause damage to rice transplanted at a depth of $2 \mathrm{~cm}$, but severely damaged rice transplanted at zero $\mathrm{cm}$. We previously suggested

\footnotetext{
* To whom correspondence should be addressed. E-mail: yamatos2@sc.sumitomo-chem.co.jp (C) Pesticide Science Society of Japan
}

that PC-1 was a prodrug and converted to 1-[1-(3,5dichlorophenyl)-1-methylethyl]-4-methyl-3-phenyl-3pyrrolin-2-one (PC-2) ${ }^{2}$ which was found by Kumiai Chemical Industry Co., Ltd./Ihara Chemical Industry Co., Ltd. (Fig. 1). ${ }^{4,5)} \mathrm{PC}-1$ was safer than PC-2 for transplanted rice, although it had less herbicidal activity than PC-2 in a greenhouse test. $^{2)}$

PC-1 has a methoxycarbonyl group as a feature of its chemical structure (Fig. 1). Methoxycarbonyl groups are easily metabolized to carboxyl groups in plants, which is important for herbicidal activity. ${ }^{6}$

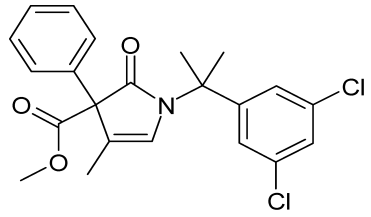

$\mathrm{PC}-1$

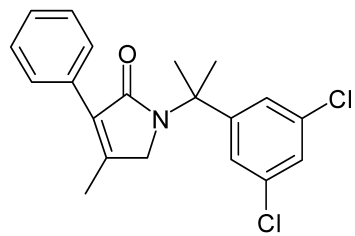

PC-2
Fig. 1. Chemical structures of $\mathrm{PC}-1$ and $\mathrm{PC}-2$. 
We examined the effects of four metabolic inhibitors on the phytotoxicity of PC-1 in early watergrass and rice to confirm the involvement of esterase in the phytotoxicity of PC-1.

\section{MATERIALS AND METHODS}

\section{Chemicals}

The inhibitors used were triphenyl phosphate (TPP), tributyl phosphate (TBP), fenitrothion (MEP) and 1-aminobenzotriazole (ABT). TPP, TBP and MEP were purchased from Wako Pure Chemical Industries, Ltd., and ABT and porcine liver esterase (lyophilized powder) from Sigma Chemical Co.

\section{Germination of Early Watergrass and Rice}

Early watergrass seeds were stored in tap water at $4^{\circ} \mathrm{C}$ for a month to break their dormancy. The seeds were germinated at $30^{\circ} \mathrm{C}$ in the dark and used for both hydroponics and greenhouse tests.

Rice (Oryza sativa L. cv. Nipponbare) seeds were germinated at $30^{\circ} \mathrm{C}$ for 2 days in the dark and used for a hydroponics test. The germinated seeds were sown and grown in a greenhouse up to the 2-leaf stage, and used for a greenhouse test.

\section{Growth Response}

The growth response of early watergrass and rice to test compounds (PC-1 and PC-2) with or without metabolic inhibitors was examined in both hydroponics and greenhouse tests.

\subsection{Hydroponics test}

Five germinated seeds of early watergrass and rice were placed in a test solution $(2 \mathrm{ml})$ in a glass vial $(2.5 \mathrm{~cm}$ in diameter). The test solution was prepared by addition of a test compound dissolved in acetone to deionized water. The final concentration of acetone was $0.1 \%(\mathrm{v} / \mathrm{v})$. A blank test solution containing the same amount of acetone was also prepared. The vials were placed in a growth chamber at $28^{\circ} \mathrm{C}$ (light 20,000 lux, $16 \mathrm{hr}$; dark, $8 \mathrm{hr}$ ). Shoot length was measured 7 days after treatment. For the dose-response determination, the experiment was repeated four times with two replications. The $\mathrm{I}_{50}$ value of a test compound was analyzed with the log-logistic equation using JMP ver. 5.01J software (SAS Institute Japan). The equation relating the biological response $\mathrm{Y}$ to the compound's concentration $\mathrm{X}$ was $\mathrm{Y}=\mathrm{C}+(\mathrm{D}-\mathrm{C}) /\{1+$ $\left.\left(\mathrm{X} / \mathrm{I}_{50}\right)^{\mathrm{b}}\right\}$ where $\mathrm{C}$ is the lower limit of inhibition, $\mathrm{D}$ the upper limit of inhibition, $b$ the slope, and $\mathrm{I}_{50}$ the concentration that gives 50\% inhibition. ${ }^{7)}$ In metabolic inhibitor experiments, each inhibitor (TPP, TBP, MEP and ABT) dissolved in acetone was added to the solution containing PC-1. This experiment was repeated twice with two replications.

\subsection{Greenhouse test}

Temperatures in a greenhouse were maintained between $18^{\circ} \mathrm{C}$ (night) and $30^{\circ} \mathrm{C}$ (day). Early watergrass was grown in $100 \mathrm{~cm}^{2}$ plastic pots filled with paddy soil (light clay, $\mathrm{pH} 5.7$, organic matter content $1.98 \%$ ). PC-1 was dissolved in $20 \%$ $(\mathrm{v} / \mathrm{v})$ acetone containing $0.4 \%(\mathrm{w} / \mathrm{v})$ Tween 20 , and the solu- tion was added to flooding water in a pot at the 2.5-leaf stage of the plants. TPP or MEP was applied just after PC-1. The water was maintained at a depth of about $4 \mathrm{~cm}$ after the treatment. Aboveground parts of the plants were harvested 3 weeks after treatment and dry weights were measured. The experiment was repeated twice with two replications.

Rice at the 2-leaf stage was transplanted to the surface (at a depth of zero $\mathrm{cm}$ ) of flooded soil in a $100 \mathrm{~cm}^{2}$ plastic pot. PC1 and a metabolic inhibitor (TPP or MEP) were applied just after the transplanting. Treatment and assessment methods were the same as in the early watergrass experiments.

\section{Porcine Esterase Reaction}

Porcine liver esterase (lyophilized powder, 41 units/mg solid) was used for the enzyme assay. The reaction mixture $(2 \mathrm{ml})$ consisted of $100 \mathrm{mM}$ potassium phosphate buffer $(\mathrm{pH} 7.5)$, the enzyme preparation (10 units), $5 \mu \mathrm{M}$ PC-1 and zero to $10 \mu \mathrm{M}$ TPP. PC-1 and TPP dissolved in DMSO were added to the enzyme preparations. The final concentration of DMSO in the reaction mixture was less than $1 \%(\mathrm{v} / \mathrm{v})$. The reaction mixture was incubated for $2 \mathrm{hr}$ at $37^{\circ} \mathrm{C}$, and the reaction was stopped by the addition of dichloromethane $(5 \mathrm{ml})$. After vigorous shaking for one minute, the dichloromethane layer was concentrated to dryness. The residue was dissolved in acetonitrile $(0.5 \mathrm{ml})$ and analyzed using a reversed-phase HPLC system equipped with a Wako Handy ODS column ( $\Phi 4.6 \times 150 \mathrm{~mm}$ ) (Wako Pure Chemical) preceded by a guard column (LiChrospher 100 RP-18 encapped) (Merck). The mobile phase was acetonitrile and distilled water $(7: 5, \mathrm{v} / \mathrm{v})$. The detection wavelength was $254 \mathrm{~nm}$. Concentrations of PC1 and PC-2 in the sample were calculated from the standard curve of each compound.

\section{Metabolism of PC-1 in Early Watergrass and Rice Plants}

Plants were grown in paddy soil up to the 2.5-leaf stage in a greenhouse. The roots of the plants were washed with tap water, followed by distilled water. The plants $(6 \mathrm{~g} \mathrm{FW})$ were incubated in Hoagland and Arnon nutrient solution containing $25 \mathrm{nM} \mathrm{PC}-1(250 \mathrm{ml})$ for 6 days in a growth chamber at $25^{\circ} \mathrm{C}$ (light 3000 lux, $16 \mathrm{hr}$; dark, 8hr). The nutrient solution was renewed 3 days after treatment. The leaves $(4 \mathrm{~g} \mathrm{FW})$ of treated plants were excised 6 days after treatment and homogenized in acetone $(100 \mathrm{ml})$ with a polytron homogenizer (Ystral). The homogenate was filtered and the filtrate was concentrated to about $5 \mathrm{ml}$ under reduced pressure. Distilled water was added to the sample up to $15 \mathrm{ml}$, and then the sample was loaded onto a Chem Elut cartridge $(20 \mathrm{ml}$, Varian). PC-1 and PC-2 were eluted with hexane $(100 \mathrm{ml})$. The eluate was concentrated and applied to a Sep-Pak Plus alumina N cartridge (Waters Cooperation). The cartridge was washed with hexane : chloroform $=9: 1(\mathrm{v} / \mathrm{v})(20 \mathrm{ml})$, and then PC-1 and PC-2 were eluted with hexane:chloroform=1:1 (v/v) $(20 \mathrm{ml})$. The eluate was concentrated to dryness. The residue 
was dissolved in hexane $(5 \mathrm{ml})$ and applied to a Sep-Pak Plus silica cartridge (Waters Cooperation). After the cartridge was washed with hexane: chloroform $=9: 1(\mathrm{v} / \mathrm{v})(20 \mathrm{ml}), \mathrm{PC}-1$ and PC-2 were eluted with hexane: chloroform $=3: 1(\mathrm{v} / \mathrm{v})$ $(20 \mathrm{ml})$. The eluate was concentrated and the resulting residue was dissolved in acetonitrile $(2 \mathrm{ml})$, and analyzed by HPLC. HPLC conditions were the same as mentioned above. The recovery of PC-2 from early watergrass and rice by this analytical method was 87 and $88 \%$, respectively.

\section{RESULTS AND DISCUSSION}

\section{Characteristics of $P C-1$}

Selectivity between early watergrass and rice was examined by a hydroponics test. PC-1 was safer than PC-2 in rice plants, although the herbicidal activity of $\mathrm{PC}-1$ was weaker than that of PC-2 (Fig. 2). The $\mathrm{I}_{50}$ values of PC-1 against early watergrass and rice were 0.025 and $2.63 \mu \mathrm{M}$, respectively. On the other hand, $\mathrm{I}_{50}$ values of PC-2 against early watergrass and rice were 0.012 and $0.115 \mu \mathrm{M}$, respectively. The tolerance ratio ( $\mathrm{I}_{50}$ of rice $/ \mathrm{I}_{50}$ of early watergrass) was 104 for PC- 1 and 10 for PC-2. The introduction of a methoxycarbonyl group into the pyrrolinone structure gave greater selectivity to the compound.
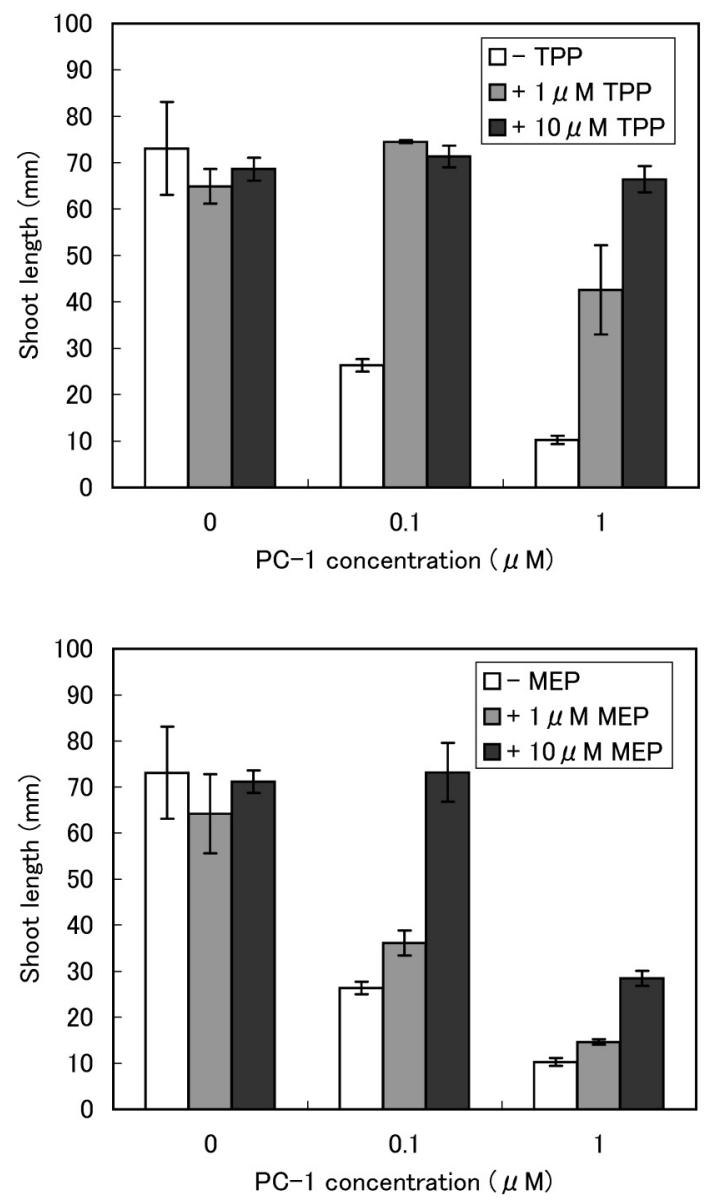

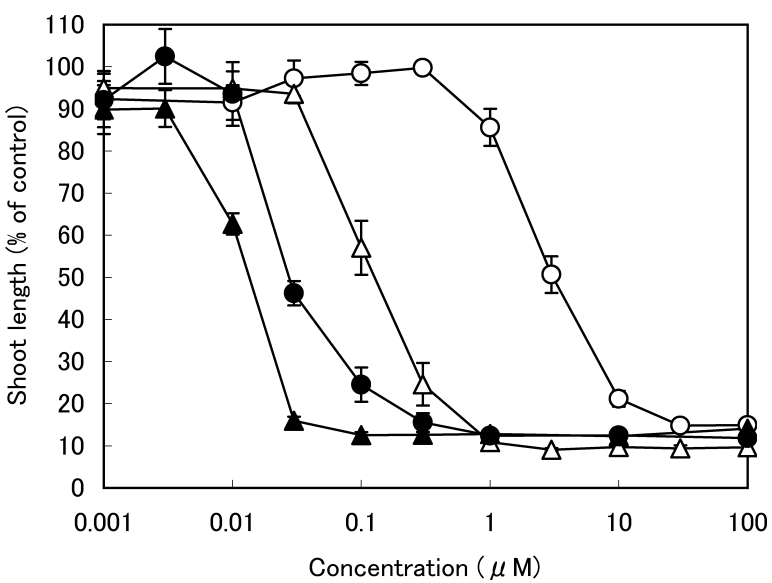

Fig. 2. Effects of PC-1 and PC-2 on the growth of early watergrass and rice.

$\mathrm{O}$, rice treated with $\mathrm{PC}-1 ; \boldsymbol{\bullet}$, early watergrass treated with $\mathrm{PC}-1 ; \triangle$, rice treated with $\mathrm{PC}-2 ; \mathbf{\Delta}$, early watergrass treated with PC-2. Average shoot lengths of control early watergrass and rice were 7.7 and $5.5 \mathrm{~cm}$, respectively. The data are the mean value of four experiments with two replications \pm SE.
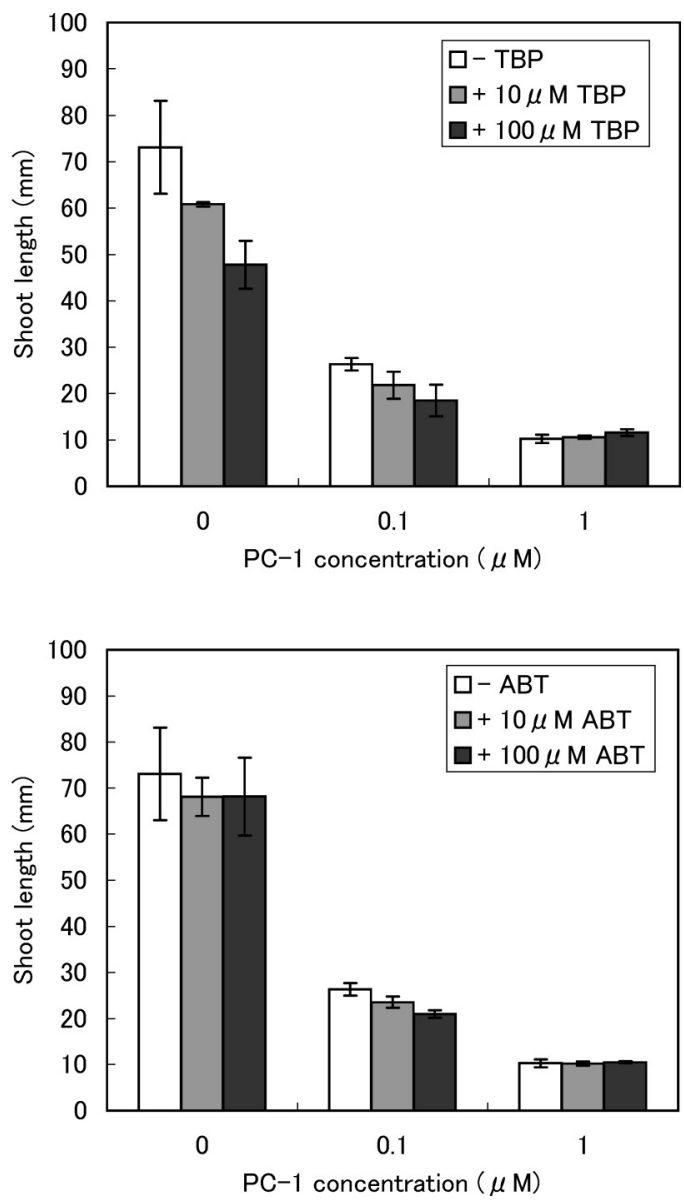

Fig. 3. Effects of metabolic inhibitors on the growth of early watergrass treated with PC-1. The data are the mean value of two experiments with two replications \pm SE. 
A

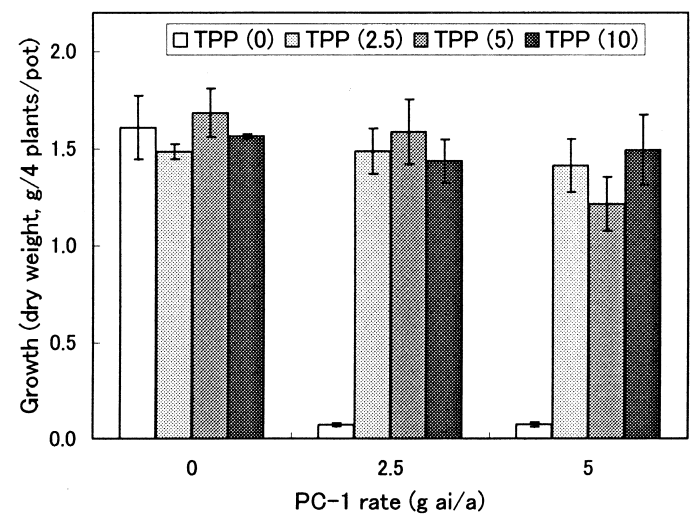

C

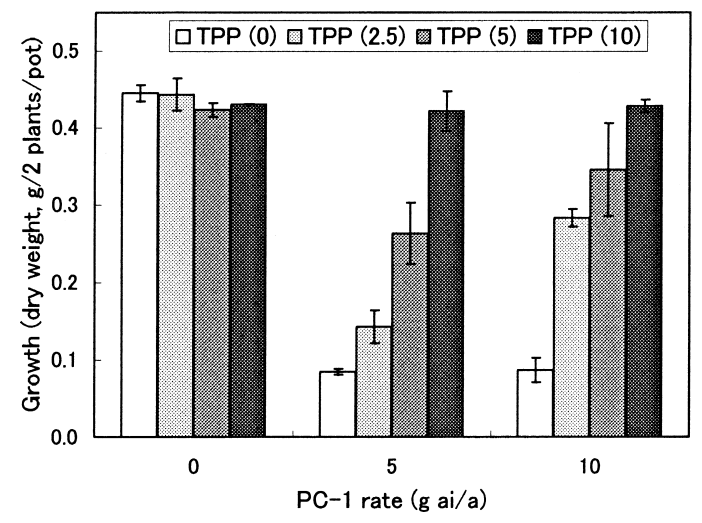

B

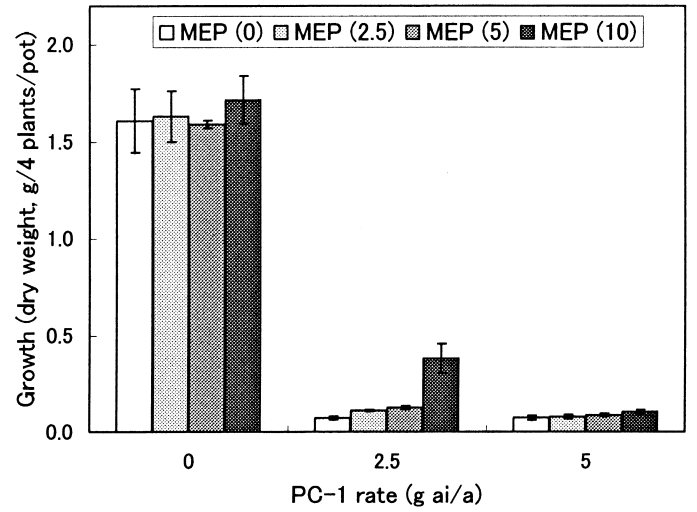

D

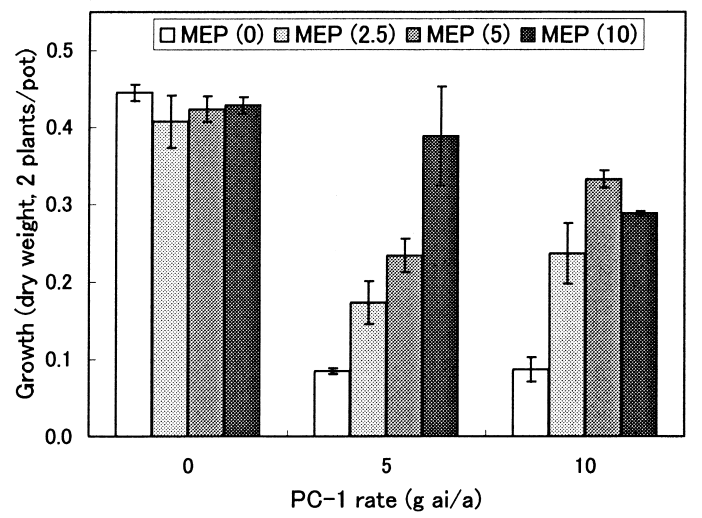

Fig. 4. Effects of TPP and MEP in combination with PC-1 on the growth of early watergrass and rice.

$\mathrm{A}$ and B, early watergrass; C and D, shallowly transplanted rice. Numbers in parentheses are treatment rate of inhibitors ( $\mathrm{g}$ ai/a). The data are the mean value of two experiments with two replications \pm SE.

2. Involvement of Esterase in the Phytotoxicity of PC-1 TPP, TBP and MEP (esterase inhibitors) and ABT (cytochrome P-450 monooxygenase inhibitor ${ }^{8,9)}$ were used to determine the enzymes involvement in the metabolism of PC1 in early watergrass. Figure 3 shows the effects of these inhibitors on PC-1's actions in early watergrass in a hydroponics test. TPP and MEP reduced the efficacy of PC-1 greatly. The addition of $10 \mu \mathrm{M}$ TPP almost reversed the growth inhibition by PC-1. TBP and ABT did not reduce the efficacy of PC-1.

The effects of TPP and MEP on the herbicidal activity of PC-1 were also examined in a greenhouse test (Figs. 4A and 4B). PC-1 was applied at a rate of 2.5 or $5 \mathrm{~g}$ ai/a which inhibits the growth of early watergrass by more than $95 \%$. TPP markedly reduced the herbicidal activity of PC-1. PC-1 at 2.5 $\mathrm{g}$ ai/a inhibited early watergrass growth by $96 \%$, but this inhibition was almost reversed by the addition of TPP (2.5-10 g ai/a). On the other hand, the reduction in herbicidal activity caused by MEP was not remarkable. The herbicidal activity of PC-2 was not affected by TPP or MEP in the greenhouse test (data not shown).

Next, the effects of TPP and MEP on the PC-1-caused damage to rice were examined (Figs. 4C and 4D). Since $10 \mathrm{~g}$ ai/a of PC-1 did not damage rice transplanted at a depth of 2 $\mathrm{cm}$, the plants were transplanted at a depth of zero $\mathrm{cm}$ (shallow transplant) and were treated with PC-1 at 5 and $10 \mathrm{~g}$ ai/a, rates causing severe damage. TPP and MEP reduced the damage in a dose-dependent manner. The reduction by TPP was similar to by MEP. However, the responses of early watergrass

Table 1. Metabolism of PC-1 to PC-2 by porcine liver esterase

\begin{tabular}{llcc}
\hline Enzyme & Inhibitor & PC-1 $(\mu \mathrm{M})$ & PC-2 $(\mu \mathrm{M})$ \\
\hline None & None & $5.18 \pm 0.10$ & ND \\
Esterase & None & $1.97 \pm 0.09$ & $3.00 \pm 0.03$ \\
Esterase & $1 \mu \mathrm{M} \mathrm{TPP}$ & $2.50 \pm 0.09$ & $2.69 \pm 0.04$ \\
Esterase & $10 \mu \mathrm{M} \mathrm{TPP}$ & $4.26 \pm 0.10$ & $0.66 \pm 0.01$ \\
\hline
\end{tabular}

The reaction mixture contained $0.1 \mathrm{M}$ potassium phosphate buffer ( $\mathrm{pH} 7.5$ ), $5 \mu \mathrm{M}$ PC-1, 10 units of porcine liver esterase and 0 to $10 \mu \mathrm{M}$ TPP. The data are the mean value of three independent experiments \pm SE. ND, not detected $(<0.06 \mu \mathrm{M})$. 
<smiles>COC(=O)C1(c2ccccc2)C(=O)N(C(C)(C)c2cc(Cl)cc(Cl)c2)C=C1C</smiles>

$\mathrm{PC}-1$

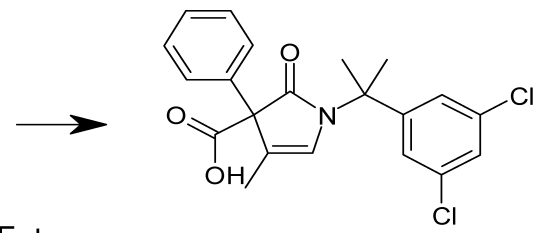

Esterase

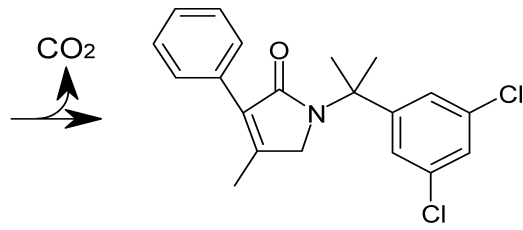

$\mathrm{PC}-2$

Fig. 5. Plausible metabolic pathway of PC-1 to PC-2.

and rice to TPP and MEP were different. Interestingly, MEP in combination with $\mathrm{PC}-1$ showed greater selectivity between rice and early watergrass than $\mathrm{PC}-1$ alone.

Furthermore, the metabolism of $\mathrm{PC}-1$ to $\mathrm{PC}-2$ by porcine liver esterase was examined. PC-1 was converted to PC-2 by the enzyme (Table 1). TPP at 1 and $10 \mu \mathrm{M}$ inhibited the formation of PC-2 by $10 \%$ and $78 \%$, respectively. The esterase heated for $10 \mathrm{~min}$ at $100^{\circ} \mathrm{C}$ failed to metabolize PC-1 (data not shown). These results indicated that esterase catalyzed PC-1 metabolism to PC-2.

The results of hydroponics, greenhouse and esterase tests suggest that $\mathrm{PC}-1$ is a prodrug and is metabolized to its active form, PC-2, by esterase in plants. Figure 5 shows a plausible metabolic pathway for PC-1. PC-1 was converted to a carboxylic acid form by esterase, and then decarboxylated to PC2.

\section{Selectivity between Early Watergrass and Rice}

Early watergrass and rice were grown in a nutrient solution containing PC-1 and the amount of PC-2 in each plant species was measured. The measurement of PC-1 failed, because other compounds from plants were co-eluted with $\mathrm{PC}-1$ in HPLC. As shown in Table 2, the amounts of PC-2 in early watergrass and rice were 1.88 and $0.47 \mathrm{nmol} / \mathrm{g}$ FW 6 days after treatment, respectively. The amount of PC-2 in early watergrass was 4 times that of rice. These results suggest that PC-2 produced in PC-1-treated plants is related to the sensitivity of early watergrass and rice to PC-1.

Cummins et al. ${ }^{10)}$ reported that esterase activity toward the herbicide diclofop-methyl was over 10-fold higher in blackgrass and 2.4-fold higher in wild oat than in wheat. Isoelectric focusing non-denaturing gel electrophoresis demonstrated that enzymatic property of esterases in wheat was different from that in weeds. In our study, since the growth response to

Table 2. The amount of PC-2 in early watergrass and rice grown in nutrient solution containing PC-1 for 6 days

\begin{tabular}{cc}
\hline Plant & PC-2 content (nmol/g FW) \\
\hline Early watergrass & $1.88 \pm 0.22 \mathrm{a}$ \\
Rice & $0.47 \pm 0.08 \mathrm{~b}$ \\
\hline
\end{tabular}

The data are the mean value of two experiments with two replications \pm SE. Means followed by a different letter are significantly different (Student's $t$-test, $P<0.05$ ).
TPP and MEP differed between the two plant species, it is possible that different kinds of esterase are involved in the activation of $\mathrm{PC}-1$ in early watergrass and rice, which causes the difference in PC-2 content between the two plant species.

Our previous study demonstrated that the depth at which rice plants were planted affected crop damage by $\mathrm{PC}-1{ }^{2)}$ The damage to shallowly transplanted rice was severer than that of normally transplanted rice $(2 \mathrm{~cm}$ depth) at more than $2.5 \mathrm{~g}$ ai/a. In addition, leaching of the irrigation water enhanced the crop damage caused by PC-1. These results suggested that the uptake of PC-1 through the roots as well as esterase activity was one of the factors of PC-1's phytotoxicity. It is speculated that $\mathrm{PC}-2$ production increased as the concentration of $\mathrm{PC}-1$ increased in plants. Further study is needed to characterize esterases that metabolize PC-1 to PC-2 in the plants and to examine the uptake of PC-1 into the plants. In conclusion, this study revealed that the esterase was involved in the phytotoxicity of PC-1 to early watergrass and rice.

\section{ACKNOWLEGEMENTS}

We are grateful to Miho Tabuchi and Atsushi Kadowaki for advice on the analysis of test compounds.

\section{REFERENCES}

1) M. Miyahara: "Weeds and Their Control in Paddy," Zenkoku Nosan Kyoiku Kyokai, Tokyo, 1992 (in Japanese).

2) T. Fusaka, S. Yamato, T. Kajiwara, H. Kamiyama, S. Itoh and Y. Tanaka: J. Pestic. Sci. 29, 339-347 (2004).

3) T. Fusaka, Y. Tanaka and A. Kadowaki (Takeda Chemical Industries, Ltd.): PCT Int. Appl. WO 00/09481 (2000) (in Japanese).

4) N. Oba, A. Ikeda, K. Matsunari, Y. Yamada, M. Hirata, Y. Nakamura, H. Karino and A. Takeuchi (Kumiai Chemical Industry Co., Ltd./Ihara Chemical Industry Co., Ltd.): Jpn. Kokai Tokkyo Koho JP 3-204855 (1991) (in Japanese).

5) N.Oba, A. Ikeda, K. Matsunari, Y. Yamada, M. Hirata, Y. Nakamura, H. Karino and A. Takeuchi (Kumiai Chemical Industry Co., Ltd./Ihara Chemical Industry Co., Ltd.): Jpn. Kokai Tokkyo Koho JP 9-278719 (1997) (in Japanese).

6) B. J. Incledon and J. C. Hall: "Regulation of Enzymatic Systems Detoxifying Xenobiotics in Plants," ed. by K. K. Hatzios, NATO ASI Ser. Vol. 37, Kluwer Academic, Dordrecht, pp. 67-82, 1997.

7) S. S. Seefeldt, J. E. Jensen and E. P. Fuerst: Weed Technol. 9, 218-227 (1995).

8) F. W. Plapp, J. W. S. Bigley, G. A. Chapman and G. W. Eddy: J. Econ. Entomol. 56, 643-649 (1963). 
9) P. R. Ortiz de Montellano and N. O. Reich: "Cytochrome P-450 Structure, Mechanism, and Biochemistry," 2nd Ed., Plenum Press, New York, 1995.
10) I. Cummins, M. Burnet and R. Edwards: Physiol. Plant. 113, 477-485 (2001). 